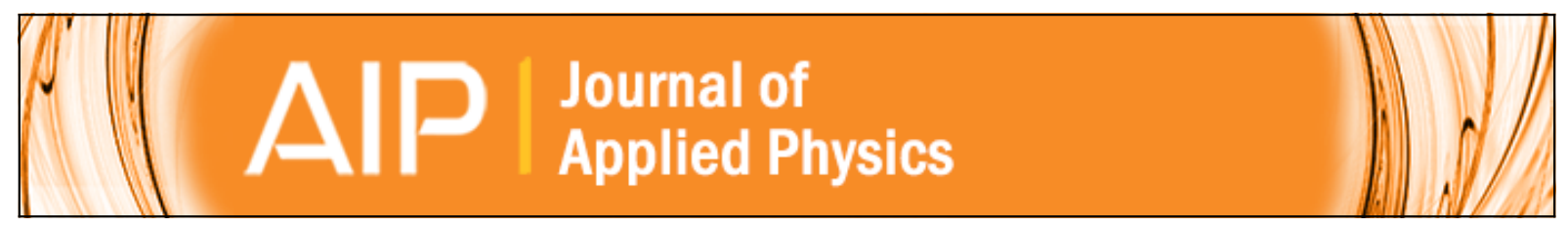

\title{
High-performance carbon nanotube coatings for high-power laser radiometry
}

Krishna Ramadurai, Christopher L. Cromer, Laurence A. Lewis, Katherine E. Hurst, Anne C. Dillon, Roop L. Mahajan, and John H. Lehman

Citation: Journal of Applied Physics 103, 013103 (2008); doi: 10.1063/1.2825647

View online: http://dx.doi.org/10.1063/1.2825647

View Table of Contents: http://scitation.aip.org/content/aip/journal/jap/103/1?ver=pdfcov

Published by the AIP Publishing

\section{Articles you may be interested in}

Atomic layer coating of hafnium oxide on carbon nanotubes for high-performance field emitters

Appl. Phys. Lett. 99, 153115 (2011); 10.1063/1.3650471

Thermal parameters of carbon nanotubes and potassium bromide composites

J. Appl. Phys. 109, 074902 (2011); 10.1063/1.3556737

Stabilized electron emission from silicon coated carbon nanotubes for a high-performance electron source J. Vac. Sci. Technol. B 29, 02B120 (2011); 10.1116/1.3565428

Highly specular carbon nanotube absorbers

Appl. Phys. Lett. 97, 163116 (2010); 10.1063/1.3502597

Femtosecond laser machining: A new technique to fabricate carbon nanotube based emitters

J. Vac. Sci. Technol. B 28, C2B38 (2010); 10.1116/1.3333515

\section{MIT LINCOLN} LABORATORY CAREERS

Discover the satisfaction of innovation and service to the nation
- Space Control

- Air \& Missile Defense

- Communications Systems \& Cyber Security

- Intelligence, Surveillance and

Reconnaissance Systems
- Advanced
Electronics
- Tactical Systems
- Homeland
Protection
- Air Traffic Control

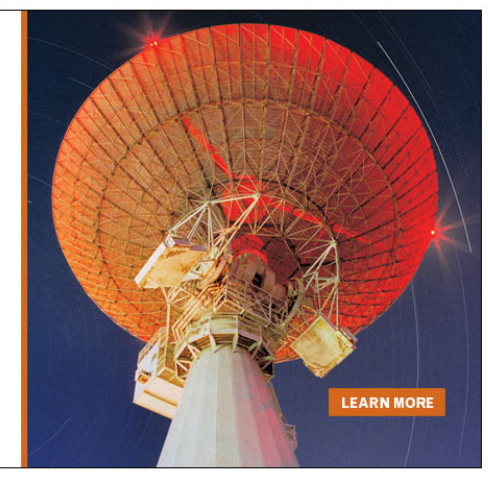




\title{
High-performance carbon nanotube coatings for high-power laser radiometry
}

\author{
Krishna Ramadurai \\ Department of Mechanical Engineering, University of Colorado, Boulder, Colorado 80309, USA
}

\author{
Christopher L. Cromer \\ National Institute of Standards and Technology, Boulder, Colorado 80305, USA \\ Laurence A. Lewis \\ James Madison University, Harrisonburg, Virginia 22807, USA \\ Katherine E. Hurst \\ National Institute of Standards and Technology, Boulder, Colorado 80305, USA
}

Anne C. Dillon

National Renewable Energy Laboratory, Golden, Colorado 80305, USA

Roop L. Mahajan

ICTAS (Institute for Critical Technology and Applied Science), Department of Engineering Science and Mechanics, Department of Mechanical Engineering, Virginia Tech, Blacksburg, Virginia 24060, USA

John H. Lehman ${ }^{\text {a) }}$

National Institute of Standards and Technology, Boulder, Colorado 80305, USA

(Received 19 September 2007; accepted 24 October 2007; published online 3 January 2008)

Radiometry for the next generation of high-efficiency, high-power industrial lasers requires thermal management at optical power levels exceeding $10 \mathrm{~kW}$. Laser damage and thermal transport present fundamental challenges for laser radiometry in support of common manufacturing processes, such as welding, cutting, ablation, or vaporization. To address this growing need for radiometry at extremely high power densities, we demonstrate multiwalled carbon nanotube (MWCNT) coatings with damage thresholds exceeding $15000 \mathrm{~W} / \mathrm{cm}^{2}$ and absorption efficiencies over $90 \%$ at $1.06 \mu \mathrm{m}$. This result demonstrates specific design advantages not possible with other contemporary high-power laser coatings. Furthermore, the results demonstrate a performance difference between MWCNTs and single-walled carbon nanotube coatings, which is attributed to the lower net thermal resistance of the MWCNT coatings. We explore the behavior of carbon nanotubes at two laser wavelengths $(1.06$ and $10.6 \mu \mathrm{m})$ and also evaluate the optical-absorption efficiency and bulk properties of the coatings. () 2008 American Institute of Physics. [DOI: 10.1063/1.2825647]

\section{INTRODUCTION}

Accurate measurements of the output power from highpower lasers pose significant measurement challenges. By high power, we refer to lasers with output power greater than $1 \mathrm{~kW}$. These measurement challenges include damage to the measurement instrument itself and nonlinear effects that are not significant at conventional laser power levels $(100 \mathrm{~W}$ or less). Water-cooled power meters are often used for high irradiance laser measurements. ${ }^{1}$ The basis of such a power meter is a radiation-absorbing surface or cavity with a black coating. The incident radiation is converted to thermal energy, which is measured to evaluate the power absorbed by the cavity. Plass et $a l^{2}$ designed a calorimeter that could accommodate up to $25 \mathrm{~kW}$ of laser power with a maximum power density of $4000 \mathrm{~W} / \mathrm{cm}^{2}$, limited by damage to the aluminum black coating. Other metal black coatings used in laser power meters and calorimeters have been reported in

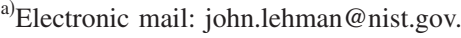

the literature. ${ }^{3-6}$ The chief limitations to these coatings are their high susceptibility to damage, low absorption efficiencies, and low thermal conductivity. Carbon nanotubes (CNTs), by virtue of their high thermal conductivity, ${ }^{7-9}$ excellent mechanical properties, ${ }^{10,11}$ and flat spectral response over a wide wavelength range, ${ }^{12,13}$ serve as an attractive absorber coating alternative for high irradiance lasers.

In the present work, we present the performance results of single-walled carbon nanotubes (SWCNTs) and multiwalled carbon nanotubes (MWCNTs) airbrushed on copper substrates exposed to continuous-wave laser power at 1.06 and $10.6 \mu \mathrm{m}$. Commercially available CNTs dispersed in chloroform are sprayed onto a mirror-finish copper substrate. The sample is then placed in a water-cooled test stand and exposed to a $1.06 \mu \mathrm{m}$, neodymium-doped yttrium aluminum garnet (Nd:YAG) laser capable of reaching a maximum power of $1.25 \mathrm{~kW}$. The power absorbed by the coating is evaluated by measuring the increase in the cooling water temperature along with the mass flow rate of the water. A beam splitter and a monitor power meter determine the power incident on the sample. A commercial power meter, 
placed in a defocused part of the beam near the sample position, is used to calibrate the monitor detector. The beam is focused to a spot size of $2 \mathrm{~mm}$ and possesses a nearly flat top profile on the sample. The laser power is increased incrementally until the onset of damage to the coating is visually evident. The visual damage threshold is defined by the power density, $I_{\mathrm{vd}}$, at which changes to the coating become apparent, characterized by the first occurrence of sparks. Increasing the incident power beyond visual damage eventually leads to a significant drop in the absorption efficiency $\eta$ due to destruction of the coating exposing the underlying copper. The power density, at which this significant reduction in absorption efficiency is registered, is referred to as $I_{\text {ad }}$. Sprayed carbon paint samples are also tested for comparison with the CNT samples.

\section{MATERIALS AND METHODS}

\section{A. Coating preparation}

Commercially obtained MWCNTs and SWCNTs are used to develop the coatings. The nanotubes $(10 \%$ by weight) are dispersed in a solution of chloroform and the mixture is sonicated for $10 \mathrm{~min}$. The nanotube mixture is then sprayed (with an airbrush) onto a polished copper substrate $(62 \mathrm{~mm} \times 24 \mathrm{~mm} \times 0.8 \mathrm{~mm})$ to produce samples for damage testing. Commercial carbon-based paint sprayed on copper is also used for comparison. The samples are dried in air prior to the experiments. The thickness of the sprayed coatings prepared under identical conditions is mechanically measured to be approximately $10 \mu \mathrm{m} \pm 2 \mu \mathrm{m}$.

\section{B. Experimental setup for damage threshold evaluation}

Damage testing is performed at two different wavelengths. For irradiation at $10.6 \mu \mathrm{m}$, a $2.5 \mathrm{~kW} \mathrm{CO}$ laser, capable of a power density of $10000 \mathrm{~W} / \mathrm{cm}^{2}$, is used as the source for local heating and eventual damage. The laser passes through a beam expander and then is incident on an optical chopper $(60 \mathrm{~Hz}, 1550$ rotations/min) that splits the beam, one portion of which is monitored by an air-cooled power meter. The other beam portion is allowed to pass through a faceted zinc selenide $(\mathrm{ZnSe})$ lens with a focal length $38.1 \mathrm{~mm}$. The lens converges different parts of the beam onto the sample surface. The ZnSe lens thus acts as a homogenizer of the beam intensity prior to incidence on the sample.

In a similar but separate experiment with the $1.25 \mathrm{~kW}$ $\mathrm{Nd}$ :YAG laser operating at $1.06 \mu \mathrm{m}$, the beam from the fiber optic cable is split into two components by a beam splitter. One component is monitored by the power meter and the other portion is allowed to pass through a converging lens. The resulting beam is passed through an aperture (diameter $10.2 \mathrm{~mm}$ ) and a focusing lens arrangement to define the beam size on the sample.

For calibration of both lasers, the sample holder is replaced with a water-cooled power meter to determine the fraction of the power that would eventually be focused on the target. This allows the determination of a calibration factor, which, when multiplied with the reading from the power meter, provides the incident power on the sample. Experiments with the samples are repeated for successive increments in powers until visual damage to the coating appears.

\section{Raman spectroscopy evaluation}

Raman spectroscopy measurements are performed in the backscattering configuration with $7 \mathrm{~mW}$ from an argon-ion laser providing $488 \mathrm{~nm}(2.54 \mathrm{eV})$ excitation. A $55 \mathrm{~mm}$ telephoto lens is employed both to focus the beam to $\sim 0.25 \mathrm{~mm}^{2}$ area and to collect the Raman-scattered light. The scattered light is analyzed with a $270 \mathrm{~mm}$ grating spectrometer equipped with a liquid-nitrogen-cooled chargecoupled detector and a holographic notch filter.

\section{Thermal resistance measurements}

A test setup based on a modified version of ASTM D5470 has been developed to measure the thermal resistance of the fabricated samples at room temperature. The sample is sandwiched between two aluminum cylinders (diameter $19.05 \mathrm{~mm}$ and length $20 \mathrm{~mm}$ ). A patch heater serves as the heat source. The lower cylinder, mounted on a copper cooling block, serves as the heat sink. The temperature of the water circulating inside the cooling block is maintained at $15^{\circ} \mathrm{C}$ using a chiller. An aluminum foil is placed on the cooling block to enable better contact between the cooling block and the cylinder. The cylinders are wrapped in styrofoam to minimize heat loss. Differential thermocouples, $T$-type, are inserted at predefined locations in the aluminum cylinders. A nanovoltmeter is used to read the voltage directly from the differential thermocouples, which is then translated to a temperature drop using Seebeck's law. A double-acting pneumatic actuator connected to a series of valves is used to apply pressure ranging from 5 to 70 psi. Copper substrates, $19.05 \mathrm{~mm}$ diameter $(0.8 \mathrm{~mm}$ thick), are electrodischarge-machined from a sheet of copper with a mirror finish. These samples are then sprayed with MWCNTs and SWCNTs separately for the measurements. The differential thermocouples monitor the heat flow into the interface and also the losses along the cylinders. The difference in the heat flux in the hot and cold cylinders is evaluated to be $4 \%-5 \%$ and we attribute this variation to the heat loss from the side of the cylinder. One-dimensional heat flow through the sample is assumed, neglecting the heat loss from the sides. The readings are taken $60 \mathrm{~min}$ following the power input to the patch heater. The duration is based on a variation of less than $0.0001 \mathrm{mV}$ in the nanovoltmeter signal. It should be noted here that the signal across the interface is generally in the range of $0.1 \mathrm{mV}-0.4 \mathrm{mV}$, and that across the other thermocouples is in the range of $0.005 \mathrm{mV}-0.015 \mathrm{mV}$. While the signal at each point is monitored, it is allowed to stabilize for $5 \mathrm{~min}$ prior to recording. The differential thermocouple across the interface monitors the temperature drop, which along with the calculated average input heat flux and the sample thickness is used to evaluate the thermal resistance of the interface. 

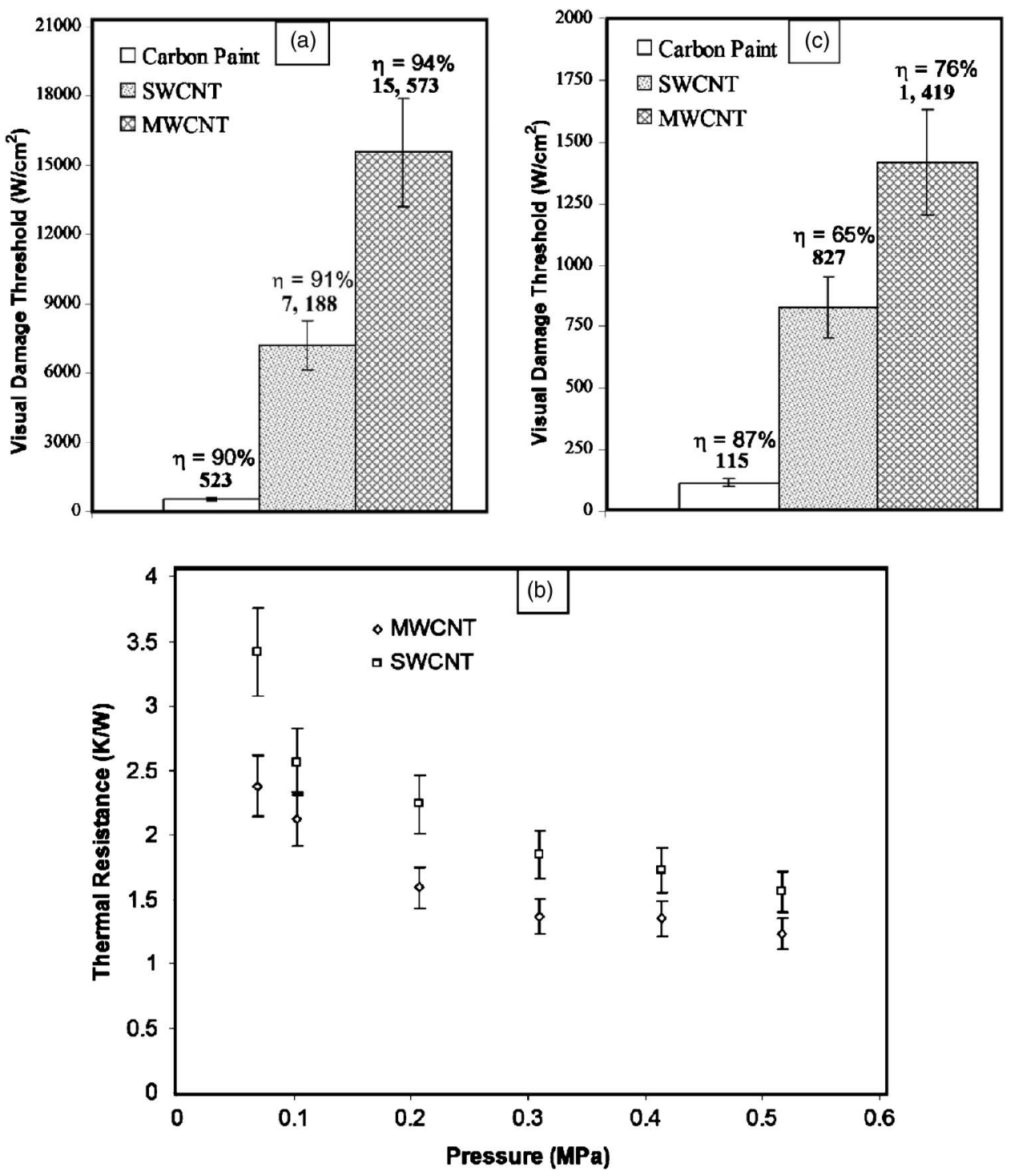

FIG. 1. (a) Comparison of $I_{\mathrm{vd}}$ for the sprayed coatings upon irradiance at $1.06 \mu \mathrm{m}$. The numbers on the bars list $I_{\mathrm{vd}}$ and $\eta$ for the respective samples. (b) Comparison of thermal resistance of the sprayed SWCNT and MWCNT samples as a function of applied pressure. (c) Comparison of $I_{\mathrm{vd}}$ for the sprayed coatings upon irradiance at $10.6 \mu \mathrm{m}$. The numbers on the bars list $I_{\mathrm{vd}}$ and $\eta$ for the respective samples.

\section{RESULTS AND DISCUSSION}

From Fig. 1(a), $I_{\mathrm{vd}}$ of MWCNTs and SWCNTs is evaluated to be 15573 and $7188 \mathrm{~W} / \mathrm{cm}^{2}$, respectively, which are higher than that of carbon paint coatings by a factor of 30 and 14, respectively. Both samples are found to be associated with high values of $\eta$ at $I_{\mathrm{vd}}$. The high threshold suggests enhanced thermal transport through the coating thickness to the flowing water. As a result, the coating surface temperature is maintained below the oxidation temperature of CNTs, leading to its high damage resistance. The MWCNT coatings are thus able to maintain an $\eta$ over $90 \%$ at high power densities of up to $15500 \mathrm{~W} / \mathrm{cm}^{2}$.

MWCNTs exhibit twice the damage threshold demonstrated by SWCNTs, which is counterintuitive, as SWCNTs are generally known to have higher thermal conductivities compared to MWCNTs. This trend has been observed in independent thermal measurements with aligned MWCNT ${ }^{14}$ and SWCNT films, ${ }^{15,16}$ however there could be a wide variation in the measured conductivities depending on the presence of noncarbon content and structural order of the tubes. To interpret this difference, we performed thermal resistance measurements as a function of applied pressure on the sprayed MWCNT and SWCNT samples using the ASTM D5470 ${ }^{17}$ thermal resistance test method. Results from thermal resistance measurements are shown in Fig. 1(b). The results indicate the thermal resistance of SWCNTs is $44 \%$ higher than that of MWCNTs of similar thickness at an applied pressure of $0.069 \mathrm{MPa}$. The variation could be higher in the absence of external pressure, which is more representative of the laser experiments. The difference in resistance caused a relatively higher temperature drop across the SWCNT coating and thereby resulted in a lower damage threshold.

The sprayed samples are also exposed to a $2.5 \mathrm{~kW}$ carbon dioxide $\left(\mathrm{CO}_{2}\right)$ laser operating at $10.6 \mu \mathrm{m}$ to explore the wavelength dependence of the damage threshold. Figure 1(c) compares $I_{\mathrm{vd}}$ of the coatings at $10.6 \mu \mathrm{m}$. The MWCNTs and SWCNTs outperform the carbon paint by a factor of 12 and 7 , respectively. The damage thresholds at $1.06 \mu \mathrm{m}$ are 9 to 11 times larger than the corresponding values at $10.6 \mu \mathrm{m}$.

We use optical and electron microscopy in conjunction with Raman spectroscopy to provide insight into the presence of morphological and structural changes in the sprayed samples. Figures 2(a) and 2(b) show optical microscopy im- 

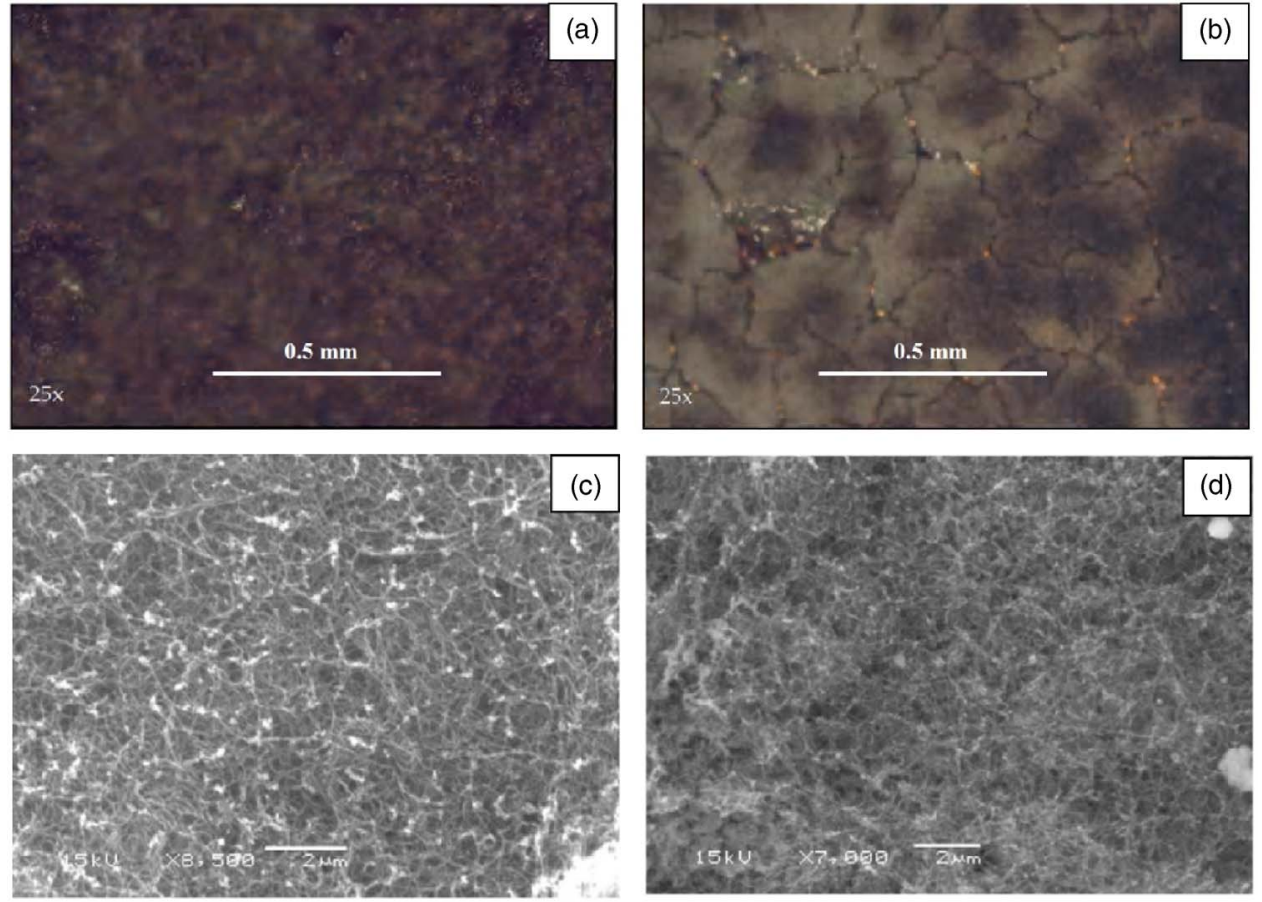

FIG. 2. (Color online) (a) Optical microscope image of unexposed carbon paint sample. (b) Optical microscope image of carbon paint sample exposed to irradiance, $I_{\mathrm{ad}}$, at $10.6 \mu \mathrm{m}$. (c) Scanning electron microscope (SEM) image of unexposed MWCNTs. (d) SEM image of MWCNTs exposed to irradiance, $I_{\text {ad }}$, at $10.6 \mu \mathrm{m}$. (e) SEM image of nanotubes present at the edge of the exposed regions of the MWCNT coating upon irradiance, $I_{\mathrm{ad}}$, at $1.06 \mu \mathrm{m}$.

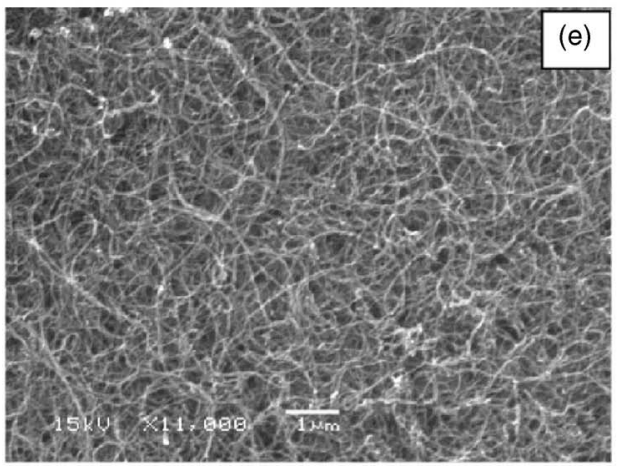

ages of the unexposed and damaged carbon paint sample subjected to irradiance, $I_{\text {ad }}$, at $10.6 \mu \mathrm{m}$. The exposed sample has cracks on the surface and the bright spots are most likely due to the presence of fused silica beads in the carbon paint. At high incident power levels, the temperature of the surface increased to a value high enough to melt the silica beads and rupture the coating. Figures 2(c) and 2(d) show the unexposed and exposed regions of the MWCNT coating at irradiance, $I_{\mathrm{ad}}$, approximately $3000 \mathrm{~W} / \mathrm{cm}^{2}$, from the $10.6 \mu \mathrm{m}$ $\mathrm{CO}_{2}$ laser. Figure 2(e) shows nanotubes present at the edge of the exposed regions of the MWCNT coating subjected to $I_{\text {ad }}$ at $1.06 \mu \mathrm{m}$. These electron microscopy images reveal no obvious qualitative differences in the irradiated nanotube samples.

MWCNT coatings demonstrate the highest damage threshold among the tested samples. To understand the different damage behavior between SWCNTs and MWCNTs, we invoke an effective medium approximation (EMA) to model the two systems. The EMA considers each nanotube to be embedded in an infinite medium with a uniform dielectric constant. Other researchers ${ }^{18,19}$ have used the EMA to model the effective dielectric constant of aligned CNT films. We use the relations for $s$-polarized light ${ }^{19}$ and evaluate the complex dielectric function of planar graphite ${ }^{20,21}$ as an ad- equate representation of the indices of CNTs. ${ }^{20}$ We then evaluate the absorbance ${ }^{22}$ of the sprayed CNTs at right angles to the axis of the graphitic planes at both 1.06 and $10.6 \mu \mathrm{m}$. Figure 3 shows the absorbance of the CNT film as a function of the volume fraction of CNTs (fill factor) for both wavelengths. The trends of the model are consistent with our experimental observations in that the absorption is

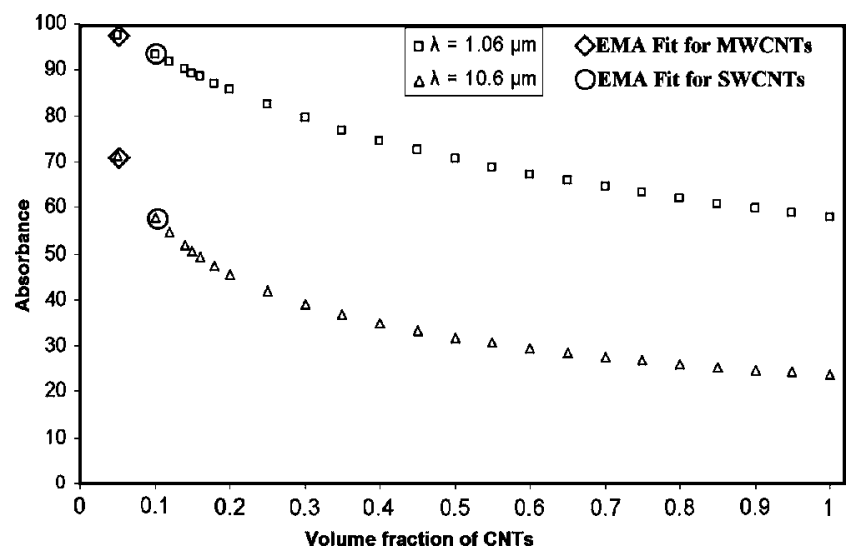

FIG. 3. Calculated absorption of CNT films as a function of the volume fraction of CNTs at 1.06 and $10.6 \mu \mathrm{m}$ using the EMA model for SWCNTs and MWCNTs. 
higher at $1.06 \mu \mathrm{m}$ than at $10.6 \mu \mathrm{m}$. The EMA model provides good agreement with the experimental absorption values for MWCNTs and SWCNTs at a fill factor of 0.05 and 0.1 , respectively. The difference in the fill factor suggests a higher coating density for the SWCNTs and also explains its relatively higher thermal resistance compared to MWCNTs, as evidenced by the measurements.

To interpret the variation in the damage threshold, we calculate the penetration depth of the radiation at both wavelengths using Beer's law and the measured value for the absorption efficiency, $\eta$, at $I_{\mathrm{vd}}$. The penetration depth at both wavelengths is significantly less than the presumed coating thickness of approximately $10 \mu \mathrm{m}$, and thus cannot explain the lower damage threshold observed at $10.6 \mu \mathrm{m}$ irradiance. A faceted $\mathrm{ZnSe}$ lens is used as a homogenizer, resulting in a nonuniform beam profile that may have partly contributed to the damage threshold difference.

Recent investigations have given valuable insights into the effects of transferring large amounts of energy from laser radiation to a carbon nanotube lattice. ${ }^{23-25}$ The studies indicate a restructuring of the CNTs at high incident power densities into energetically favorable nanostructures. In addition, a high defect density in the structure of the tubes is also apparent at high-energy densities. These findings motivated an investigation of the structural changes occurring in the MWCNT coating by use of Raman spectroscopy. Figures 4(a) and 4(b) show Raman spectra of the exposed and unexposed regions of the coating, normalized to the intensity of the $G$ band, upon exposure to $I_{\mathrm{ad}}$ at 10.6 and $1.06 \mu \mathrm{m}$, respectively. The " $G$ band" at $1500-1650 \mathrm{~cm}^{-1}$ is a compilation of bands originating from the in-plane vibrational modes of carbon in the curved graphite lattice, while the " $D$ band" at $\sim 1350 \mathrm{~cm}^{-1}$ is generated by symmetry-lowering effects such as defects, tube ends, or the presence of non-nanotube carbon impurities. ${ }^{26}$ A broad $D$ band is characteristic of the presence of non-nanotube carbon impurities such as amorphous carbon or nanocrystalline graphite. ${ }^{27}$ The full width at-half-maximum (FWHM) of the $D$ band, listed in Fig. 4(a), decreases from 43.61 to $38.40 \mathrm{~cm}^{-1}$ for the sample exposed to the irradiance at $10.6 \mu \mathrm{m}$ and is therefore consistent with the removal of carbon impurities in the MWCNT sample. A similar trend is observed with irradiance, $I_{\text {ad }}$, at $1.06 \mu \mathrm{m}$, wherein the FWHM of the $D$ band decreases from 47.92 to $37.72 \mathrm{~cm}^{-1}$, listed in Fig. 4(b). The $D$ band/ $G$ band intensity ratio $(D / G)$ provides a relative measure of the amount of defects and the degree of graphitization in the MWCNT sample. ${ }^{26}$ The $D / G$ ratio for the spectra changes upon irradiance, $I_{\mathrm{ad}}$, at both 1.06 and $10.6 \mu \mathrm{m}$. This suggests that the MWCNTs are subjected to structural changes by laser irradiation. Furthermore, a shoulder at $1625 \mathrm{~cm}^{-1}$ becomes more apparent in the MWNT $G$-band spectra, perhaps simply due to the removal of non-nanotube carbon impurities. Conversely, it is possible that specific tubes are more susceptible to damage and are lost upon laser irradiance. Because of these morphology changes of CNTs under irradiation, a systematic Raman spectroscopy study is currently underway to monitor the evolution of the secondary peak in the $G$ band as a function of increasing laser irradiance.
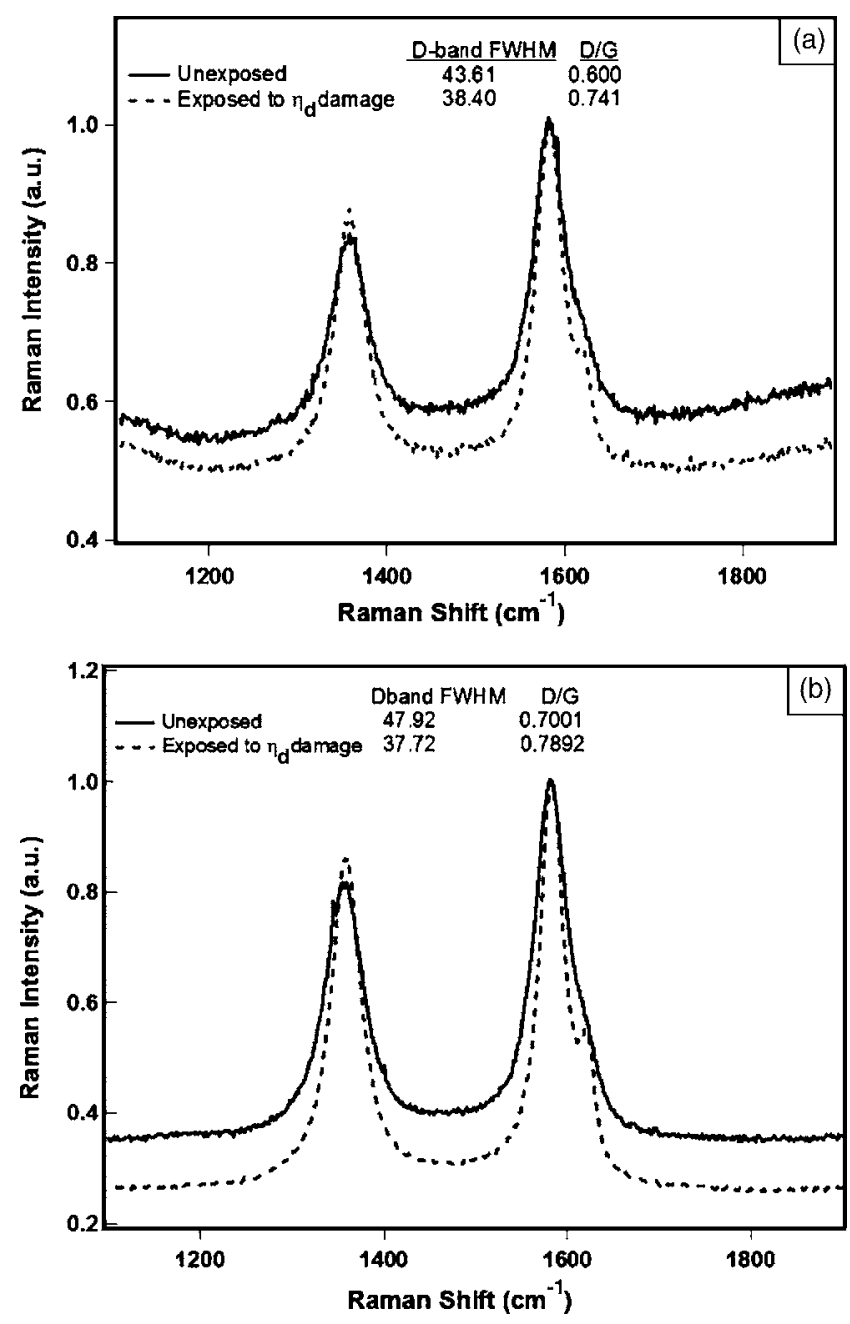

FIG. 4. (a) Raman spectra, normalized to the intensity of the $G$ band, of the exposed and unexposed regions of the coating upon irradiance, $I_{\text {ad }}$, at $10.6 \mu \mathrm{m}$. (b) Raman spectra, normalized to the intensity of the $G$ band, of the exposed and unexposed regions of the coating upon irradiance, $I_{\text {ad }}$, at $1.06 \mu \mathrm{m}$.

\section{CONCLUSIONS}

In conclusion, we demonstrate visual damage thresholds in excess of $15000 \mathrm{~W} / \mathrm{cm}^{2}$ with MWCNT coatings at $1.06 \mu \mathrm{m}$ irradiance. The corresponding visual damage threshold at $10.6 \mu \mathrm{m}$ is over $1400 \mathrm{~W} / \mathrm{cm}^{2}$. MWCNTs have a damage threshold higher than that of carbon paint by over an order of magnitude at both wavelengths, and also demonstrate absorbance over $90 \%$ at $1.06 \mu \mathrm{m}$. Due to its lower net thermal resistance, the MWCNT coating has a higher threshold compared to the SWCNT coating. An EMA absorbance model is in good agreement with the measured absorbance values for SWCNTs and MWCNTs coatings. Raman spectroscopy shows that laser irradiation of a MWCNT coating removes amorphous carbon. The presence of a secondary peak in the $G$ band of the exposed MWCNT sample is suggestive of structural modifications to the nanotube structure, which is also supported by the change in the $D / G$ intensity ratio. The high absorption efficiency of MWCNTs, coupled with their high laser thermal threshold, holds great promise for absorber coatings for measurements associated with high power lasers. 


\section{ACKNOWLEDGMENTS}

We thank the CU-NIST seed grant program for providing financial support to this work. We also thank Dr. Xiaoyu $\mathrm{Li}$ (NIST, Boulder, CO) for his assistance with the experimental setup.

${ }^{1}$ S. R. Gunn, J. Phys. E 6, 105 (1973).

${ }^{2}$ W. Plass, A. Voss, N. Schmid, and A. Giesen, Proc. SPIE 2870, 298 (1996).

${ }^{3}$ D. B. Betts, F. J. J. Clarke, L. J. Cox, and J. A. Larkin, J. Phys. E 18, 689 (1985).

${ }^{4}$ D. J. Advena, V. T. Bly, and J. T. Cox, Appl. Opt. 32, 1136 (1993).

${ }^{5}$ N. Nelms and J. Dowson, Sens. Actuators, A 120, 403 (2005).

${ }^{6}$ J. H. Lehman, J. E. Theocharous, G. Eppeldauer, and C. Panell, Meas. Sci. Technol. 14, 916 (2003).

${ }^{7}$ J. Hone, M. C. Llaguno, and N. M. Nemes, Appl. Phys. Lett. 77, 666 (2000).

${ }^{8}$ P. Kim, L. Shi, A. Majumdar, and P. L. Mceuen, Phys. Rev. Lett. 87, 215502 (2001).

${ }^{9}$ S. Berber, Y.-K. Kwon, and D. Tomanek, Phys. Rev. Lett. 84, 4613 (2000).

${ }^{10}$ A. Krishnan, E. Dujardin, T. W. Ebbesen, P. N. Yianilos, and M. J. Treacy, Phys. Rev. B 58, 14013 (1998).

${ }^{11}$ M. M. Treacy, T. W. Ebbesen, and J. M. Gibson, Nature (London) 381, 678 (1996).

${ }^{12}$ J. H. Lehman, C. Engtrakul, T. Gennett, and A. C. Dillon, Appl. Opt. 44, 483 (2005)

${ }^{13}$ E. Theocharous, R. Deshpande, A. C. Dillon, and J. Lehman, Appl. Opt.
45, 1093 (2006).

${ }^{14}$ X. Hu, A. A. Padilla, J. Xu, T. S. Fisher, and K. E. Goodson, J. Heat Transfer 128, 1109 (2006).

${ }^{15}$ J. E. Fischer, W. Zhou, J. Vayro, M. C. Llaguno, C. Guthy, and R. Haggenmueller, J. Appl. Phys. 93, 2157 (2003).

${ }^{16}$ M. J. Casavant, D. A. Walters, J. J. Schmidt, and R. E. Smalley, J. Appl. Phys. 93, 2153 (2003).

${ }^{17}$ ASTM D 5470-95, "Standard Test Methods for Thermal Transmission Properties of Thin Thermally Conductive Solid Electrical Insulation Materials," 1995.

${ }^{18}$ F. J. Garcia-Vidal, J. M. Pitarke, and J. B. Pendry, Phys. Rev. Lett. 78, 4289 (1997)

${ }^{19}$ W. Lu, J. Dong, and Z.-Y. Li, Phys. Rev. B 63, 033401 (2000).

${ }^{20}$ L. Henrard and Ph. Lambin, J. Phys. B 29, 5127 (1996).

${ }^{21}$ A. Borghesi and G. Guizzetti, in Graphite $(C)$ in Handbook of Optical Constants of Solids, edited by E. D. Palik (Academic, San Diego, 1991), Vol. II, p. 449.

${ }^{22}$ R. Siegel and J. Howell, Thermal Radiation Heat Transfer, 4th ed. (Taylor \& Francis, New York, 2002), Vol. I, Chap. 3, p. 71.

${ }^{23}$ P. Corio, P. S. Santos, M. A. Pimenta, and M. S. Dresselhaus, Chem. Phys. Lett. 360, 557 (2002).

${ }^{24}$ R. Z. Ma, B. Q. Wei, C. L. Xu, J. Liang, and D. H. Wu, Carbon 38, 636 (2000).

${ }^{25}$ P. D. Kichambare, L. C. Chen, C. T. Wang, K. J. Ma, C. T. Wu, and K. H. Chen, Mater. Chem. Phys. 72, 218 (2001).

${ }^{26}$ A. C. Dillon, A. H. Mahan, P. A. Parilla, J. L. Alleman, M. J. Heben, K. M. Jones, and K. E. H. Gilbert, Nano Lett. 3, 1425 (2003).

${ }^{27}$ A. C. Dillon, M. Yudasaka, M. S. Dresselhaus, and J. Nanosci, Nanotechnology 4, 691 (2004). 